\title{
PRE-ACCLIMATIZATION FOR HIGH ALTITUDE SOJOURNS IN HYPOXIC CHAMBERS
}

\author{
Thomas Küpper ${ }^{1,2(A-G)}$, Volker Schoeffl ${ }^{2,3,4(A-G)}$ \\ ${ }^{1}$ Institute for Occupational and Social Medicine, RWTH Aachen University, Aachen, Germany \\ ${ }^{2}$ Medical Commission of the Union Internationale des Associations d'Alpinisme (UIAA MedCom) \\ ${ }^{3}$ Department of Sportorthopedics, Klinikum Bamberg, Bamberg, Germany \\ ${ }^{4}$ Department of Trauma Surgery, Friedrich Alexander University Erlangen-Nuremberg, Nuremberg, Germany
}

\begin{abstract}
More and more people go to high altitude without enough time for proper acclimatization. If there is a lack of time for any reason hypoxic chambers may be used for pre-acclimatization to avoid altitude diseases. Since there are different protocols and the data differ, there is no general consensus about the standard how to perform pre-acclimatization by simulated altitude. We review different types of exposure and focus target groups which may get benefit from pre-acclimatization. We suggest to perform pre-acclimatization by sleeping some nights at a simulated altitude which follows the altitude profile of the "Gold Standard" for high altitude acclimatization. Until there are more detailed data about intermittent hypoxia this method should provide the best effect.
\end{abstract}

Key words: acclimatization, hypoxia, simulated altitude, acute mountain sickness

\section{Introduction}

High altitude sojourns are more and more common for many people, but many of them go too fast too high, mainly because of a subjective or (sometimes) objective lack of time. Such sojourns include mountaineers or skiers, businessmen travelling to Colorado, South America and other regions, tourists visit historic sites in the Andes, scientists work at telescopes in the Andes or at Hawaii, or workers in the world's highest mines are located at 5,300 m in Chile. Several 10,000 trekkers hike the Annapurna Trek or to the Solo Khumbu region every year (Fig. 1). The highest points of these treks are at about $5,400 \mathrm{~m}$ (Thorong La 5,416 m, Everest Base Camp 5,364 m, Kalar Pattar 5,545 m). Time pressure is the reason why Mt. Kilimanjaro $(5,860 \mathrm{~m})$ is considered as the most dangerous mountain in the world. More and more people try to climb it within 3-4 days and only the minority reaches the summit healthy, although there would be beautiful alternatives to the most common used so-called "Coca cola route" (Fig. 2) [1]. This group pressure is the argument of the tour operators to offer treks where the participants climb far too high without adequate acclimatization (Fig. 3). Businessmen are another group with limited time or unforeseen trips to high altitude [2]. Principally correct acclimatization was, is, and will ever be the "Gold Standard" for any altitude sojourn [3]. But if immediate ascent cannot be avoided or work in isobaric hypoxia $>4,000 \mathrm{~m}$ (rsp. $12.5-13 \% \mathrm{O}_{2}$ at 1 bar) must be done for a whole day, pre-acclimatization avoids altitude-related diseases and stabilizes the performance of the persons.

The main problem for the body is the management of the decreased oxygen pressure. Without such mechanisms an altitude of about 1,500 m could not be survived without accidental oxygen [4]. Fortunately there are multiple systems to manage the problem, some of them reacting within seconds or minutes (e.g. pulse rate, breathing frequency, breathing volume, shift of the oxygen binding curve), some others in days or weeks (e.g. circulation, haemoconcentration, ventilatory acclimatization) or even years or generations (e.g. vascular growth) (Fig.4) [5]. The effect of some of these acute adaptations is enormous: the shift of $\mathrm{pH}$ by respiratory alkalosis at high altitude from 7.2 to 7.6 at a partial oxygen pressure $\left(\mathrm{pO}_{2}\right)$ of $30 \mathrm{mmHg}$ increases $\mathrm{O}_{2}$-saturation $\left(\mathrm{SaO}_{2}\right)$ from 28 to $57 \%$ [4]. A central role for the regulation of many of these mechanisms has a substance called hypoxia inducible factor $1 \alpha$ (HIF $1 \alpha)$ [6]. HIF1 $\alpha$ is produced permanently and metabolised via hydroxylation and proteosomal lysis. If hypoxia occurs, the system switches to another pathway within seconds: by a massive phosphorylization HIFla becomes the active metabolite which joins the hypoxic binding sites and induces the increased transcription of the HIF1a-dependent genes [7-8].

The vulnerability of a person by AMS, high altitude pulmonary oedema (HAPE), and high altitude cerebral oedema (HACE) is influenced by the hypoxic pulmonary ventilatory drive (HVD), although this correlation is not strong enough to use HVD as a predictor 


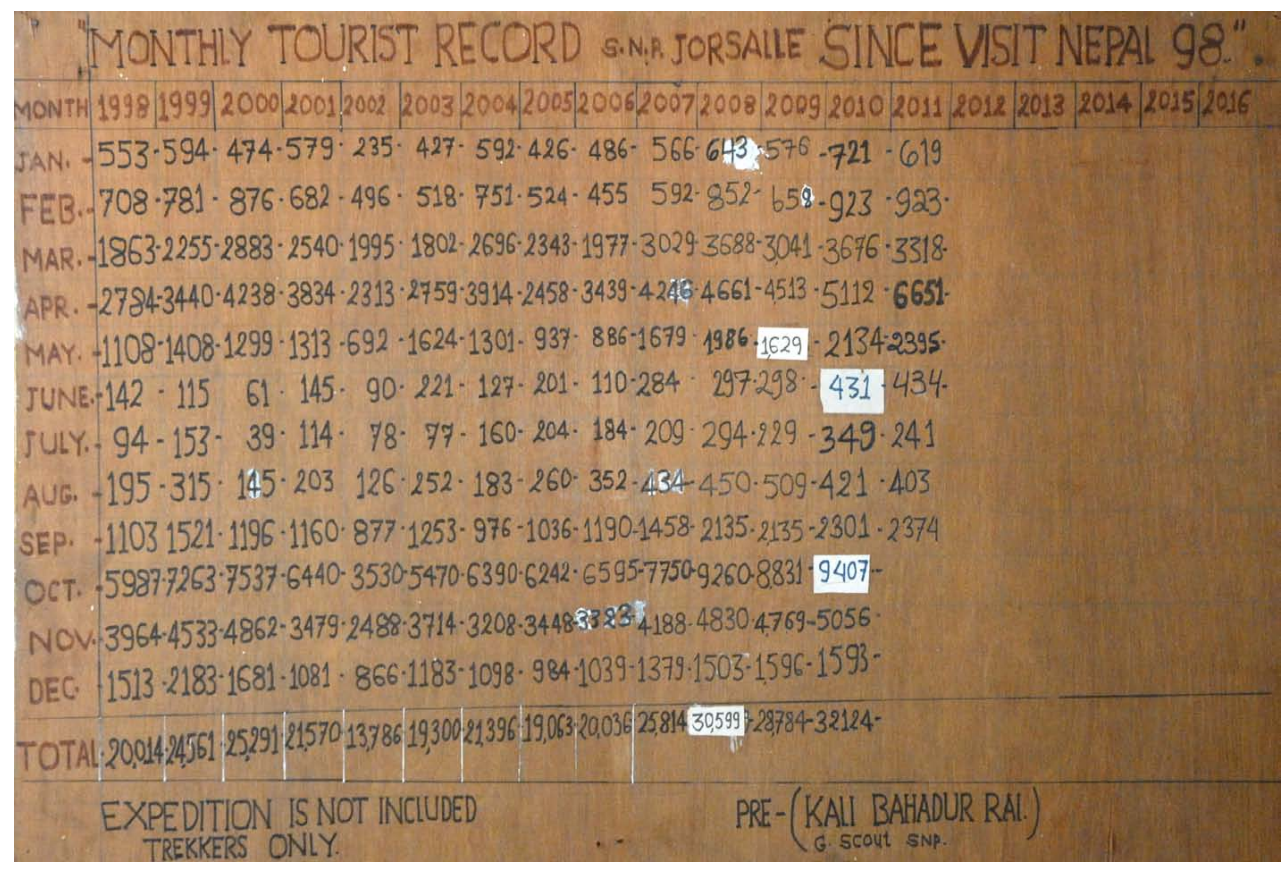

Fig. 1. Number of persons who visited the Solo Khumbu region (Sagharmatha National Park, Nepal) 1998-2011 (by courtesy of the National Park Office)

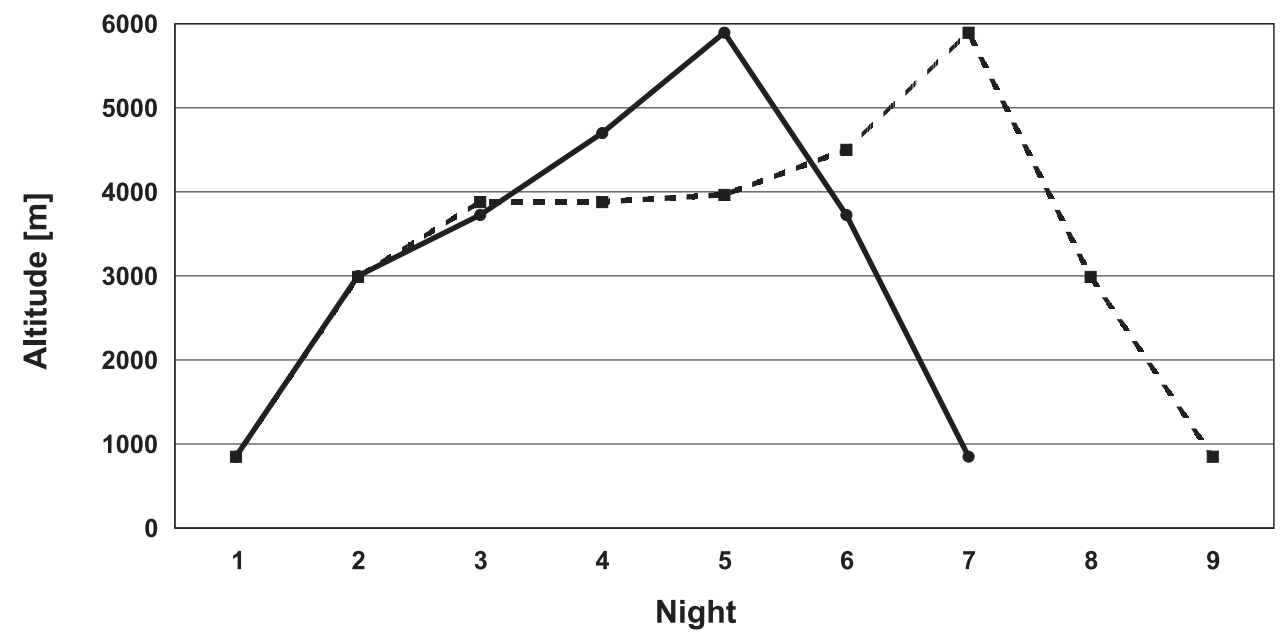

Fig. 2. Ascent profile of Mt. Kilimanjaro (5,890m): "Coca cola route" (line) and alternative ascent via Shira Plateau, Southern Circuit, and Barafu Bivouac (dotted line), which follows a nearly ideal ascent profile.

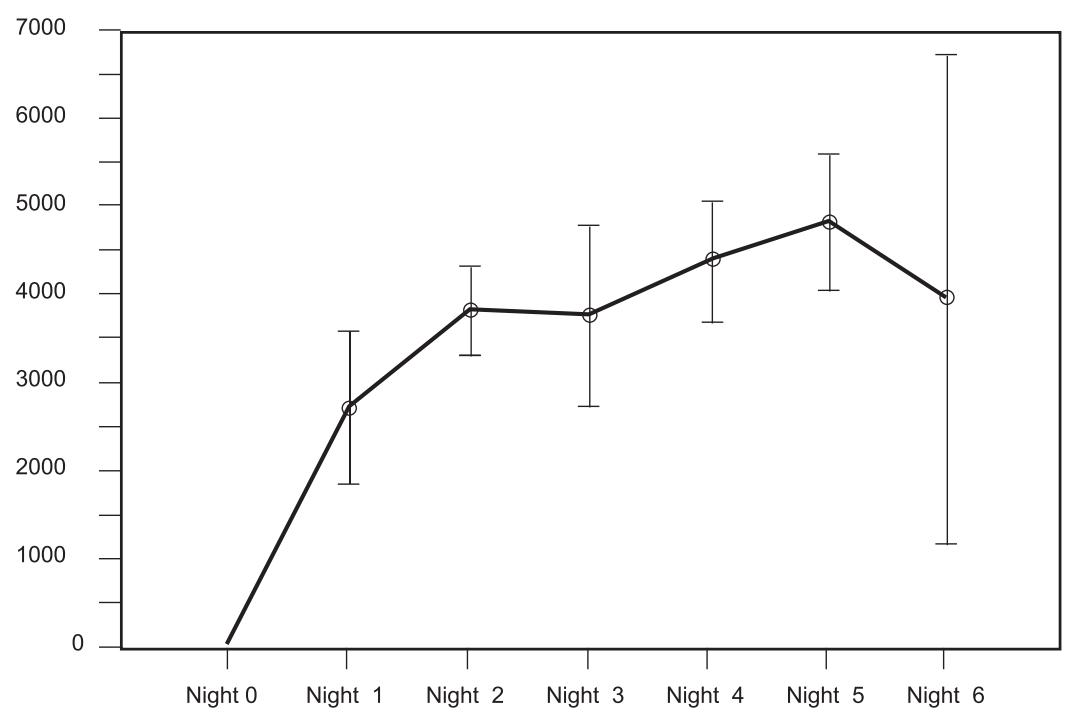

Fig. 3. Altitude profiles of 19 tours, offered by the three biggest German tour operators (from [14]) 


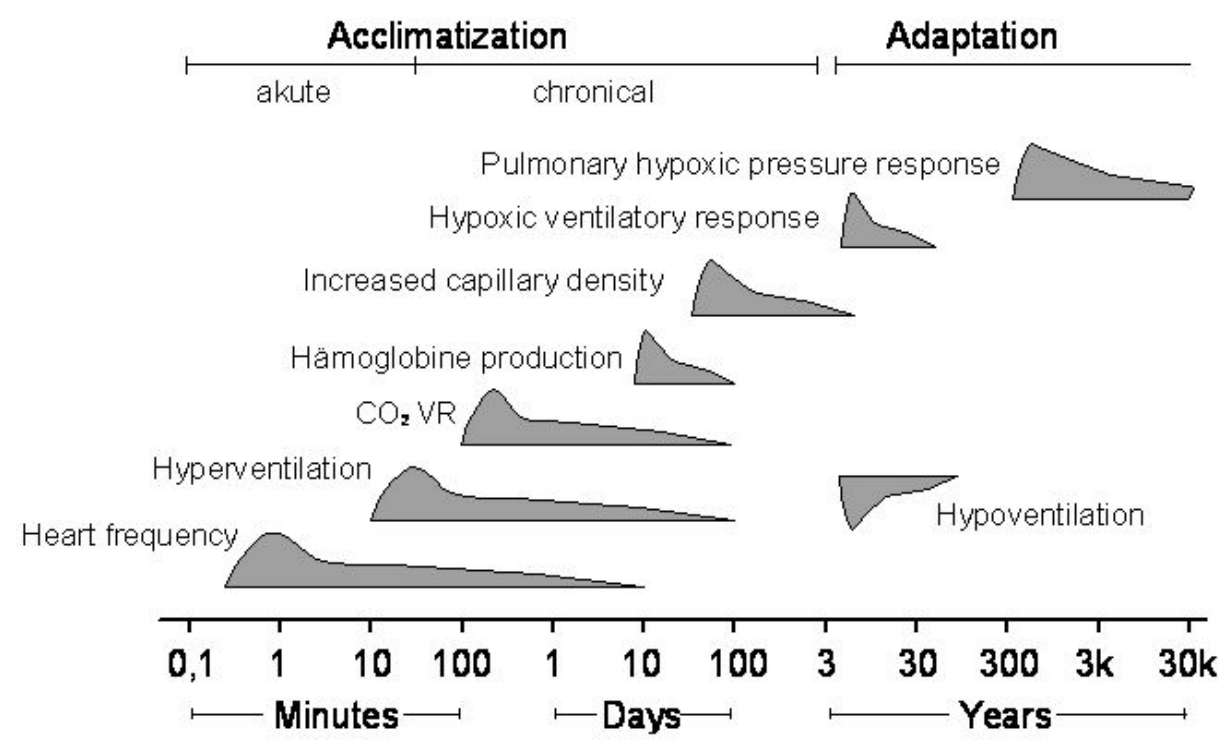

Fig. 4. Mechanisms of acclimatization (examples, from [14])

of a person's ability to cope with high altitude conditions. HVD is genetically determinated. Although a multitude of attempts were done in the past, e.g. for arterial oxygen saturation $\left(\mathrm{SaO}_{2}\right)$ [9], a combination of $\mathrm{SaO}_{2}$ and individual performance, and others, there is no reliable prediction of individual altitude tolerance except for the person's history: if he/ she has tolerated high altitude in the past quite well, it is likely that there will be no problem at other sojourns, if the person acclimatizes properly.

But there are other important factors which are responsible for the individual fitness at altitude and the risk of altitude-related diseases as the limitation of diffusion capacity of the alveolar membrane or of minute breathing volume [10], the erythrocytes form, plasticity, size, and age [11], or increased plasma volume or low haematocrit respectively [12]. Again, all of them do not allow to predict the individual altitude or hypoxia tolerance.

For pre-acclimatization an extensive literature research was performed in international databases (e.g. PubMed) with the keywords intermittent hypoxia, simulated altitude, acute mountain sickness, hypoxic ventilatory response, mountaineering, trekking, acclimatization, hypoxic chambers, and isobaric hypoxia. Papers cited in reviews but not listed in the databases and other papers which were known to the authors but also not listed in the databases were also included if there was a substantial contribution to the topic of this paper.

\section{Which group may benefit from pre-acclimatization?}

Knowledge about acclimatization strategies and ascent profiles are mainly based on empirical data, but these include $>1000$ years of high altitude experience [13]. Nevertheless, there is no doubt that proper acclimatization according to the "Gold Standard" (recommendations published in $[3,14]$ and a multitude of other papers) is the best way to prepare the body for high altitude. There is no evidence that this will change in the next 100 or so years, since any genetic adaptation, if there is some interbreeding between lowlanders and highlanders in the course of the so-called "globalization", will take several generations. Acclimatization is of special importance for any lowlander who will sleep at altitude $>2,500 \mathrm{~m}$ or who will stay at $>4,000 \mathrm{~m}$ for 1-3 hours. Persons with pre-existing conditions may need special advice or in some cases restrictions [15]. "Gold Standard" includes slow ascent $(+500 \mathrm{~m}$ sleeping altitude every second day or a maximum of $+1,000 \mathrm{~m}$ per week, beginning at 2,500 $\mathrm{m}$ ), sleep with slightly increased upper body, no breathing with pressure and workload below the anaerobic threshold during acclimatization phase $[3,14]$.

If such an ideal ascent profile cannot be realized for any objective reason (e.g. airport of destination at high altitude (e.g. in the Andes or Tibet), urgent and unexpected work has to be done at high altitude like rescue or service, or "critical" mountains where a good altitude profile is difficult to be realized (e.g. Ruwenzori Mountains), a pre-acclimatization for 24-48 hours should be possible for most industrial or business tasks or for travelling. In contrast, the setting for most rescue operations is different. For normal alpine (helicopter) rescue pre-acclimatization is not necessary, mainly because the crews stay too short at altitude and most of them are partially acclimatized. But if international operations should be assisted by a back-up team of unacclimatized lowlanders, the time necessary to organize such operations should be used to pre-acclimatize the team members. 
Beside these groups, there are even more people who may benefit from pre-acclimatization: persons with known problems of acclimatization, although the altitude profile was perfect ("slow acclimatizers"), or elite sport teams who are facing competitions at high altitude, which was first discussed for the Olympic Games at Mexico City in 1968.

\section{Pre-acclimatization - how should it be performed?}

Some of the mechanisms listed above prevent altitude diseases in the early stage of altitude exposure, while others are responsible for the metabolic stabilization of the body for long stays at altitude [5]. Those which develop over several generations are not of interest for the topic presented here. For preacclimatization it does not matter whether it is done by an exposure of the body to real (hypobaric) or simulated altitude (hypobaric or - easier - isobaric), but all procedures are limited in duration. Therefore any pre-acclimatization will influence exclusively those mechanisms which are responsible for the early stage of high altitude sojourns, i.e. to avoid acute mountain sickness (AMS).

It is well known that there are minor physiological differences between isobaric and hypobaric hypoxia. This was already described by Paul Bert 140 years ago and confirmed later by others $[16,17]$. But these differences do not have any consequences for the tactics of acclimatization, neither in isobaric conditions nor in the mountains $[18,19]$.

The main difference between pre-acclimatization at "real" altitude or in a hypoxic chamber is, that real altitude means, that the person will stay at a given altitude for some time (continuous exposure), while in most cases the stay in a hypoxic chamber will last some hours per day or an overnight stay. Unfortunately there is not much knowledge about acclimatization by intermittent hypoxia with some hours per day in hypoxic environment and therefore actually there is no standard for pre-acclimatization in hypoxic chambers by intermittent hypoxia of some hours. As Burtscher et al. mentioned in detail, studies performed so far show a benefit if the persons are exposed 1-4 hours per day at a corresponding altitude of about $4,000 \mathrm{~m}$ $\left(\mathrm{FiO}_{2}=12 \%\right)$ [20]. On the other hand Bärtsch et al. didn't find any difference in the incidence of AMS of persons ascending to Margherita Hut $(4,560 \mathrm{~m})$ after some days with $12 \% \mathrm{O}_{2}$ for 4 hours (personal communication, May 2009). But as stated by Mutschler the subjects of Bärtsch's study didn't follow exactly the altitude profile of the study for several reasons (weather etc.; Mutschler, personal communication, July 2009), which is a major limitation of the study.

Several other recent studies deal with the topic of simulated altitude, in contrast to the legendary "Operation Everest II" in most cases with intermit- tent hypoxia. Most studies available so far deal with limited numbers of subjects and with significant differences in exposure (altitude, duration of hypoxia and duration normoxia between the hypoxic phases). This prevents a direct comparison of the results. Nevertheless, since Richalet used a hypoxic chamber when he was preparing the Everest expedition in the early 90's [21], some other studies indicate the benefit of preacclimatization by intermittent hypoxia to minimize the risk to suffer from AMS [22,23]. In most cases the hypoxic exposure was equivalent to an altitude of $4000 \mathrm{~m}$, but the duration per day and the total period of exposure was very different ( 3 and more hours per day for 6-20 days) [21-24]. There was no difference between exposure combined with some or without activity reported [23]. At moderate altitude there was no significant influence on several physiological factors by intermittent hypoxia [25], but several changes as usual in normal ("real") hypoxia in the mountains were found when the exposure exceeded a corresponding altitude of $2500 \mathrm{~m}$ [21,23,26-28]. In some investigations an increase of performance $[21,23,24]$ or mood status was found [29]. Intermittent hypoxia also increased the vagotonus [30]. Some data indicate that at least 1 week of exposure may be necessary to induce significant pre-acclimatization [25]. In contrast to Katayama's study significant acclimatization was found after 25 days of exposure only [31]. The most prominent effects of intermittent hypoxia with simulated altitude were found for HVD, hyperventilation and arterial oxygen saturation [21-24,27,28,30-33].

Summarized the knowledge about the influence of intermittent hypoxia and here especially the optimal "profile" of equivalent altitude, duration of exposure, the number of exposures and the pause between them on acclimatization AMS, and other factors is not yet clear. Therefore we suggest to follow "traditional" rules for acclimatization and to sleep in hypoxic conditions for some nights $[3,14]$. Although there are no double-blind controlled studies, there is evidence that the interruption of hypoxia during the day (when the subjects sleep in hypobaric hypoxia only) is of minor effect compared to 24 hrs hypoxia. Our non-systematic data of about 100 mountaineers who summitted Mt. Kilimanjaro (5,890 m), Aconcagua $(6,962 \mathrm{~m})$, and other relatively high trekking peaks and some expedition summits do not indicate a significant lesser acclimatization (indicated by higher incidence of AMS or failing to reach the summit) when compared to others who spent a couple of days at altitude for acclimatization.

Principally any pre-acclimatization should follow the recommendations of the "Gold Standard" [3]. This can be done in hypoxic chambers as well as during some days in a mountain hut. The latter is more charming, but unfortunately not always realistic. 
How high will the final altitude be and shall the preacclimatization be combined with activity? What's your goal? Just to pre-acclimatize to avoid AMS or to improve your performance? For the latter planning is crucial: VGEF and mitochondriosis increase only by high intensive training at about 3,650 $\mathrm{m} \mathrm{[34]} \mathrm{and}$ the "threshold" for erythropoietin increase is at about $2,100-2,500 \mathrm{~m}[35,36]$. An increase of $+5 \%$ of erythrocyte volume may need at least $400 \mathrm{hrs}$ (3-4 weeks) at $2,500-3,000 \mathrm{~m}$ and the anaerobic system may get more benefit by altitude than the aerobic system $[37,38]$.

The so-called "slow acclimatizers" are a special problem for preventive altitude medicine. Except for the person's history of previous altitude sojourns as mentioned above there are no procedures available which allow to detect slow acclimatizers with a positive predictive value which is acceptable. For example the hypoxic ventilatory drive, for large collectives well known to be inverse correlated with an increased risk for problems of acclimatization and AMS, cannot be used as predictor because its positive predictive value is only about $60 \%[39,40]$. The monitoring of $\mathrm{SaO}_{2}$ as described by Thomas and many others is limited by the same problem [9]. Pulse frequency cannot be used as a predictor, but it may be used to monitor the acclimatization: although there are no data there is evidence that slow acclimatizers should have normal pulse rate as normal persons have when they are completely acclimatized for the respective altitude.

Up to now the only chance to identify "slow acclimatizers" is a careful and detailed history of the person's altitude sojourns and the problems which have arised. Any person who suffered significantly from AMS symptoms although the altitude profile was acceptable or who complained about sleep disturbances significantly more than his or hers companions at the same altitude should be suspected to be "slow acclimatizers". The same should be suspected if a person suffered form HAPE at surprising low altitude $(2,500-3,000 \mathrm{~m})$ or if a person suffered from recurrent HAPE. It is well accepted that slow acclimatizers should follow a more "defensive" altitude profile than other mountaineers - but unfortunately there are no data or any consensus what "more defensive" is (survey in [14]). Until more detailed data are available we suggest to add at least one more day to every altitude of the profile until an altitude of $4,000 \mathrm{~m}$ is reached. Above this altitude the acclimatization process of slow acclimatizers is highly individual and should be monitored clinically (pulse rate, AMS symptoms or Lake Louise Score [41]).

The final altitude of pre-acclimatization depends on the altitude profile later in reality and on the time which is planned to reach that altitude. If a person wants to climb a mountain, the days of ascent can be included in the altitude profile of pre-acclimatization.
This is impossible if the person has to go to altitude at once, e.g. the businessmen or tourists to destinations in the Andes. For high destinations, work, or "critical" altitude profiles the ideal altitude to be reached by pre-acclimatization is the same (or a bit more to get a "safe zone") than the destination. Risk groups ("Slow acclimatizer") should pre-acclimatize to a final altitude which is a bit higher than the highest place planned for sleeping, but a much more "defensive" altitude profile should be chosen. As mentioned above athletes should pre-acclimatize to the height of the competition +300 $\mathrm{m}$. Both, risk group and athletes get a safe margin by doing so with a technique which is not yet evaluated in detail.

For the timing of pre-acclimatization data are limited. Possibly the best scheme for altitude up to 4000 $\mathrm{m}$ and healthy persons is as follows: $1^{\text {st }}$ night at 2,500 $\mathrm{m}$ equivalent altitude, 2. (-3.) night at 3,000 m, and 1 week later $2(-3)$ nights at 3,000 and $3,500 \mathrm{~m}$. This can be done at weekends and therefore it can be easily combined with normal life. It should be as near as possible, but not longer as $2(-3$ ?) weeks before departure.

\section{Conclusion}

Pre-acclimatization decreases the risk of altitude diseases significantly, if acute ascent cannot be avoided. To do so, a minimum of time in hypoxic environment is necessary. The special advantage of hypoxic chambers is the well controlled environment, the safety for persons with individual risks or pre-existing conditions and the easy coordination of the exposure with normal daily life and work. Nevertheless, it must be planned carefully and performed within a short period before departure. Going "not too high too fast" for optimal acclimatization is the "Gold Standard" to avoid health risks and to provide optimal performance at high altitude.

\section{Declaration of interest}

The authors report no conflicts of interest.

\section{References}

1. Karinen H, Peltonen J, Tikkanen H. Prevalence of acute mountain sickness among Finnish trekkers on Mount Kilimanjaro, Tanzania: an observational study. High Alt Med Biol 2008; 9(4): 301-6.

2. Kupper T, Milledge JS, Hillebrandt D, et al. Consensus Statement of the UIAA Medical Commission Vol.15: Work in Hypoxic Conditions. 2009 [cited 2009; Available from: www. theuiaa.org/medical_advice.html.

3. Kupper T, Gieseler U, Angelini C, et al. Consensus Statement of the UIAA Medical Commission Vol.2: Emergency Field Management of Acute Mountain Sickness, High Altitude Pulmonary Oedema, and High Altitude Cerebral Oedema. 2008 [cited 2008; Available from: www.theuiaa.org/medical_advice.html.

4. Hultgren H. High Altitude Medicine. Stanford: Hultgren Publications; 1997.

5. Ward MP, Milledge JS, West JB. High altitude medicine and physiology. London: Arnold; 2000: 326. 
6. Heinicke H, Hofer T, Wenger RH, et al. Die zelluläre Antwort auf Sauerstoffmangel. Dtsch Z Sportmed 2002; 53(10): 270-6.

7. Chilov D, Camenisch G, Kvietikova I, et al. Induction and nuclear translocation of hypoxia-inducible factor-1 (HIF-1): heterodimerization with ARNT is not necessary for nuclear accumulation of HIF-1alpha. J Cell Sci 1999; 112 ( Pt 8): 1203-12.

8. Richard DE, Berra E, Gothie E, et al. p42/p44 mitogenactivated protein kinases phosphorylate hypoxia-inducible factor 1alpha (HIF-1alpha) and enhance the transcriptional activity of HIF-1. J Biol Chem 1999; 274(46): 32631-7.

9. Thomas A. Pulsoximetrie lässt Höhenkrankheit vorzeitig erkennen. DAV Mittlg 1992: 96-7.

10. Vogt M, Flück M, Hoppeler H. "Living low - training high": Eine effektive Höhentrainingsmethode zur Verbesserung der Sportlichen Leistungsfähigkeit von trainierten Athleten. In: Sumann G, Schobersberger W, Mair P, et al., Ed. Jahrbuch 2002 der Österreichischen Gesellschaft für Alpin- und Höhenmedizin, Innsbruck: Österreichische Gesellschaft für Alpin- und Höhenmedizin; 2002: 89-104.

11. Rienzer A, Gatterer H, Faulhaber M. Intermittierende Hypoxie bei hochtrainierten Radsportlern: Auswirkungen auf die Leistungsfähigkeit und kardiovaskuläre Parameter. In: Domej W, Schobersberger W, Waanders R, et al., Ed. Jahrbuch 2005 der Österreichischen Gesellschaft für Alpin- und Höhenmedizin, Innsbruck: Österreichische Gesellschaft für Alpin- und Höhenmedizin, 2005: 153-63.

12. Merrikh AA, Lage JL. Effect of blood flow on gas transport in a pulmonary capillary. J Biomech Eng 2005; 127(3): 432-9.

13. Houston CS. Mountain sickness. Sci Am 1992; 267(4): 5862,66 .

14. Kupper T, Ebel K, Gieseler U. [Modern Mountain and Altitude Medicine]. Gentner Verlag: Stuttgart, 2010.

15. Milledge J, Kupper T. Consensus Statement of the UIAA Medical Commission Vol.13: People with Pre-Existing Conditions Going to the Mountains. 2008 [cited 2008; Available from: www.theuiaa.org/medical_advice.html.

16. Bert P. La pression barométrique. Paris: Masson, 1878.

17. Barcroft J. Respiratory function of the blood. Part I. New York: Cambridge University Press, 1925.

18. Savourey G, Launay JC, Besnard Y, et al. Normo- and hypobaric hypoxia: are there any physiological differences? Eur J Appl Physiol 2003; 89(2): 122-6.

19. Savourey G, Launay JC, Besnard Y, et al. Normo or hypobaric hypoxic tests: propositions for the determination of the individual susceptibility to altitude illnesses. Eur J Appl Physiol 2007; 100(2): 193-205.

20. Burtscher M, Gatterer H, Faulhaber M. Vorakklimatisation durch intermittierende Hypoxie. In: Haditsch B, Domej W, Schobersberger W, et al., Ed. Jahrbuch 2008 der Östereichischen Gesellschaft für Alpin-und Höhenmedizin, Innsbruck: Österreichische Gesellschaft für Alpin- und Höhenmedizin; 2008: 45-56.

21. Richalet JP, Bittel J, Herry JP, et al. Use of a hypobaric chamber for pre-acclimatization before climbing Mount Everest. Int $J$ Sports Med 1992; 13 Suppl 1: S216-20.

22. Muza S, Fulco C, Beidleman B, et al. Normobaric intermittent hypoxic exposure decrease AMS at $4300 \mathrm{~m}$ altitude (Abstract). High Alt Med Biol 2006; 4: 338.

23. Beidleman BA, Muza SR, Fulco CS, et al. Intermittent altitude exposures reduce acute mountain sickness at $4300 \mathrm{~m}$. Clin Sci (Lond) 2004; 106(3): 321-8.

24. Jones J, Muza S, Fulco C, et al. Normobaric intermittent hypoxic exposure improve foot march performance at $4300 \mathrm{~m}$ (Abstract). High Alt Med Biol 2006; 4: 333.

25. Katayama K, Sato K, Hotta N, et al. Intermittent hypoxia does not increase exercise ventilation at simulated moderate altitude. Int J Sports Med 2007; 28(6): 480-7.
26. Jones DG. An audiological survey of aircrew. J R Nav Med Sev 1988; 74: 496-502.

27. Garcia N, Hopkins SR, Powell FL. Intermittent vs continuous hypoxia: effects on ventilation and erythropoiesis in humans. Wilderness Environ Med 2000; 11(3): 172-9.

28. Garcia N, Hopkins SR, Powell FL. Effects of intermittent hypoxia on the isocapnic hypoxic ventilatory response and erythropoiesis in humans. Respir Physiol 2000; 123(1-2): 39-49.

29. Kambis K, Barnes J, Chamberlain R, et al. Short-term intermittent hypoxic exposure attenuates negative mood alterations at simulated high altitude: a pilot study (Abstract). High Alt Med Biol 2006; 4: 334.

30. Bernardi L, Passino C, Serebrovskaya Z, et al. Respiratory and cardiovascular adaptations to progressive hypoxia; effect of interval hypoxic training. Eur Heart J 2001; 22(10): 879-86.

31. Levine BD, Friedman DB, Engfred K, et al. The effect of normoxic or hypobaric hypoxic endurance training on the hypoxic ventilatory response. Med Sci Sports Exerc 1992; 24(7): 769-75.

32. Bernardi L, Passino C, Wilmerding V, et al. Breathing patterns and cardiovascular autonomic modulation during hypoxia induced by simulated altitude. J Hypertens 2001; 19(5): 947-58.

33. Lusina SJ, Kennedy PM, Inglis JT, et al. Long-term intermittent hypoxia increases sympathetic activity and chemosensitivity during acute hypoxia in humans. J Physiol 2006; 575(Pt 3): 961-70.

34. Hoppeler H, Vogt M. Hypoxia training for sea-level performance. Training high-living low. Adv Exp Med Biol 2001; 502: 61-73.

35. Ge RL, Witkowski S, Zhang Y, et al. Determinants of erythropoietin release in response to short-term hypobaric hypoxia. J Appl Physiol 2002; 92(6): 2361-7.

36. Piehl Aulin K, Svedenhag J, Wide L, et al. Short-term intermittent normobaric hypoxia - haematological, physiological and mental effects. Scand J Med Sci Sports 1998; 8(3): 132-7.

37. Meeuwsen T, Hendriksen IJ, Holewijn M. Training-induced increases in sea-level performance are enhanced by acute intermittent hypobaric hypoxia. Eur J Appl Physiol 2001; 84(4): 283-90.

38. Hendriksen IJ, Meeuwsen T. The effect of intermittent training in hypobaric hypoxia on sea-level exercise: a cross-over study in humans. Eur J Appl Physiol 2003; 88(4-5): 396-403.

39. Selland MA, Stelzner TJ, Stevens T, et al. Pulmonary function and hypoxic ventilatory response in subjects susceptible to high-altitude pulmonary edema. Chest 1993; 103(1): 111-6.

40. Lakshminarayan S, Pierson DJ. Recurrent high altitude pulmonary edema with blunted chemosensitivity. Am Rev Respir Dis 1975; 111(6): 869-72.

41. Hackett P. The Lake Louise Consensus on the definition and quantification of altitude illness. In: Sutton J, Coates G, Houston C, Ed. Advances in the Biosciences Vol. 84: Hypoxia and mountain medicine, Proceedings of the 7 th International Hypoxia Symposium, Lake Louise, Canada 1991, Oxford: Pergamon Press, 1992: 327-30.

Received: January 04, 2012

Accepted: June 04, 2012

Published: June 29, 2012

Address for correspondence:

Thomas Küpper, Prof., PhD, MD

Institute of Occupational and Social Medicine

RWTH Aachen University

Pauwelstr. 30

52074 Aachen, Germany

e-mail: tkuepper@ukaachen.de

Volker Schoeffl: Volker.Schoeffl@t-online.de

\begin{tabular}{llll}
\hline Authors' contribution & B - Data Collection & D - Data Interpretation & F - Literature Search \\
A - Study Design & C - Statistical Analysis & E - Manuscript Preparation & G - Funds Collection
\end{tabular}

